\title{
EFFICIENT STRENGTHENING TECHNIQUE TO INCREASE THE FLEXURAL RESISTANCE OF EXISTING RC SLABS
}

\author{
Everaldo Bonaldo ${ }^{1}$, Joaquim António Oliveira de Barros ${ }^{2}$, and Paulo B. Lourenço ${ }^{3}$
}

\begin{abstract}
Composite materials are being used with notable effectiveness to increase and upgrade the flexural load carrying capacity of reinforced concrete (RC) members. Near-Surface Mounted (NSM) is one of the most promising strengthening techniques, based on the use of carbon fiber-reinforced polymer (CFRP) laminates. According to NSM, the laminates are fixed with epoxy based adhesive into slits opened into the concrete cover on the tension face of the elements to strength. Laboratory tests have shown that the NSM technique is an adequate strengthening strategy to increase the flexural resistance of RC slabs. However, in RC slabs of low concrete strength, the increase of the flexural resistance that NSM can provide is limited by the maximum allowable compressive strain in the compressed part of the slab, in order to avoid concrete crushing. This restriction reduces the effectiveness of the strengthening, thus limiting the use of the NSM technique. A new thin layer of concrete bonded to the existing concrete at the compressed region is suitable to overcome this limitation. Volumetric contraction due to shrinkage and thermal effects can induce uncontrolled cracking in the concrete of this thin layer. Adding steel fibers to concrete (Steel Fiber Reinforced Concrete - SFRC), the post cracking residual stress can be increased in order to prevent the formation of uncontrolled crack patterns. In the present work, the combined strengthening strategy, a SFRC overlay and NSM CFRP laminates, was applied to significantly increase the flexural resistance of existing RC slabs. Experimental results of four-point bending tests, carried out in unstrengthened and strengthened concrete slab
\end{abstract}

\footnotetext{
${ }^{1}$ PhD Student, Dept. of Civil Engineering, Univ. of Minho, Azurém, 4800-058 Guimarães, Portugal. E-mail: bona@civil.uminho.pt

${ }^{2}$ Associate Professor, Dept. of Civil Engineering, Univ. of Minho, Azurém, 4800-058 Guimarães, Portugal. E-mail: barros@civil.uminho.pt

${ }^{3}$ Full Professor, Dept. of Civil Engineering, Univ. of Minho, Azurém, 4800-058 Guimarães, Portugal. E-mail: pbl@civil.uminho.pt
} 
strips, are presented and analyzed.

CE Database subject headings: Concrete, reinforced; Slabs; Flexural strength; Experimentation; Composite materials; Fiber reinforced materials; Fiber reinforced polymers; Laminates; Composite structures.

\section{Introduction and Background}

The Near-Surface Mounted (NSM) strengthening technique has been used in the recent years, with notable effectiveness, to increase the flexural strength (FIB 2001; Carolin 2003; Barros and Fortes 2005; Kotynia 2005; Jung et al. 2005; Liu et al. 2006) and shear resistance (De Lorenzis and Nanni 2001; Barros and Dias 2006; Barros et al. 2006) of reinforced concrete elements. The NSM technique involves the embedment of CFRP bars - of circular, square or rectangular cross-section - into grooves opened on the concrete surface. The CFRP bars are bonded to concrete using an epoxy-based adhesive.

When compared to the Externally Bonded Reinforcement (EBR) technique, the NSM technique assures a higher anchoring capacity to the FRP reinforcing material. As a consequence, a high tensile stress can be applied to the CFRP, as long as the member load carrying capacity is not limited by a premature failure mode (Blaschko and Zilch 1999; FIB 2001; Carolin 2003).

For RC slabs of low or medium concrete strength, the increment of the flexural resistance that NSM can provide might be limited by the maximum allowable compressive strain in the extreme compressed concrete fiber. This drawback can be overcome by adding a concrete layer in the compression zone of the existent slab (Walser and Steiner 1997; Barros and Sena-Cruz 2001).

To attain the desired structural performance (e.g. full composite action), the new concrete overlay and the existent concrete slab should behave monolithically. A sound bond between the new layer and the existing concrete slab can be guaranteed if a proper epoxy compound is used (Bonaldo et al. 2005a; Bonaldo et al. 2005b).

Since a thin concrete layer is enough for the aforementioned purpose, the restrained shrinkage and the temperature variation can induce uncontrolled cracking in the concrete of this layer. Adding discrete fibers to concrete, such as steel fibers, the crack widths resulting from drying restrained shrinkage can be substantially reduced. Moreover, the post cracking residual tensile strength of cement based materials can be increased by fiber addition (Barros et al. 2005), to prevent the formation of uncontrolled crack patterns. The benefits of fiber 
reinforcement can be extended to the concrete compression behavior, since concrete crushing can be delayed or even avoided for compressive strain levels attained in RC practical applications.

In the present paper, a strengthening strategy to increase the load carrying capacity of RC slabs was experimentally investigated. This strategy consists of applying CFRP laminates on the tensile bottom slab surface, according to the NSM technique, and bonding, with appropriate epoxy-based adhesive, a SFRC layer in the compression top slab surface (see Fig. 1). To assess the effectiveness of the NSM strengthening technique to increase the flexural resistance of slab strips failing in bending, four point bending tests were carried out.

\section{Experimental Program}

\section{Specimen and Test Configuration}

To assess the effectiveness of the hybrid strengthening technique for the increase of the flexural load carrying capacity of RC slabs, the slab strips represented in Fig. 2 were used, including unstrengthened (or reference) slabs and strengthened slabs (with and without concrete overlay). The test set up and the cross-section dimensions of the tested slab strips are also illustrated in Fig. 2.

The number of CFRP laminates applied in each RC slab was designed to increase the service load of the reference slabs in $50 \%$, which was assumed equal to the load producing a mid-span deflection of $\ell / 250=1800$ $\mathrm{mm} / 250=7.2 \mathrm{~mm}$, where $\ell$ is the slab span. The arrangement of the CFRP laminates and the disposition of the SFRC overlay are indicated in Fig. 2(b).

The width of the slit where the CFRP is installed usually ranges from 4.0 to $5.0 \mathrm{~mm}$ for the NSM strengthening with CFRP laminates. To assess the influence of the thickness of the adhesive layers that bond the CFRP laminate to concrete and, consequently, the influence of the adhesive deformability on the NSM strengthening performance, three different widths for the slits were considered. NSM slits having width of about $4.0 \mathrm{~mm}, 7.5 \mathrm{~mm}$ and $14.0 \mathrm{~mm}$ were selected for the hybrid slab strips, whereas a width of about $4.0 \mathrm{~mm}$ was taken for the slabs only strengthened with NSM.

The experimental program, therefore, consists of three series: SLi - reference slabs; SLiS - NSM strengthened slabs; and SLiSO - NSM and SFRC strengthened slabs. In the designation of the series, $i$ represents the number of the slab. A concrete of low-to-moderate strength was selected for the reference slabs, aiming at 
reproducing the characteristics of typical existing reinforced concrete structures. A concrete overlay thickness of approximately $30 \mathrm{~mm}$ was applied for the SFRC strengthened slabs.

\section{Measuring Devices}

Fig. 3 depicts the positioning of the sensors for data acquisition. To measure the deflection of the slab strip, five linear voltage differential transducers (LVDT \#1, LVDT \#2, LVDT \#3, LVDT \#4 and LVDT \#5) were supported in a suspension yoke (see Fig. 3(a)). LVDT \#3, placed at the slab strip mid-span, was also used to control the test at $20 \mu \mathrm{m} / \mathrm{s}$ up to the deflection of $49 \mathrm{~mm}$. After this deflection, the actuator internal LVDT was used to control the test at $25 \mu \mathrm{m} / \mathrm{s}$ displacement rate up to the failure of the slab. The total applied force ( $F$ ) was measured using a load cell $( \pm 200 \mathrm{kN}$ and accuracy of $0.5 \%)$ placed between the loading steel frame and the actuator of $600 \mathrm{kN}$ load capacity.

To measure the strains in the steel reinforcements, three electrical resistance strain gauges (SG1, SG2 and SG3) were installed on the internal steel reinforcements, according to the arrangement indicated in Fig. 3(c). Five strain gauges were installed on one CFRP laminate (SG4, SG5, SG6, SG7 and SG8) for evaluating the strain variation along the laminate, see Fig. 3(b,d). Two strain gauges (SG9 and SG10) were also bonded on the top concrete surface to determine the maximum concrete compressive strain, Fig. 3(e).

\section{Material Properties}

Table 1 and Table 2 include values, obtained from experimental tests, for the main properties of the materials used in the present work (Bonaldo et al. 2006). Two concrete batches were prepared for the same composition, with small variation in the mechanical properties $(1.5 \%$ in terms of compressive strength and $11 \%$ in terms of flexural tensile strength). In Table 1 and Table 2 the compressive strength and the static modulus of elasticity in compression were determined according to NP-EN 12 390-3 (2002) and RILEM (1994). The flexural behavior of the concretes was characterized by three-point bending tests with notched beams according to RILEM (1985) for ordinary concrete, and following the recommendations of RILEM (2002) for the SFRC overlay. The value of axial tensile strength $\left(f_{c t m}\right)$, included in Table 1, was derived from the flexural tensile strength $\left(f_{c t m, f l}\right)$, obtained from tests on notched beams, accordingly to the CEB-FIP (1993) To characterize the steel bars, uniaxial tensile tests were conducted according to the standard procedures found in NP-EN 10 002-1 (1990). Unidirectional pultruded CFRP laminates, 
specially designed to be bonded into narrow slits in concrete structures, were used in this study. The uniaxial tensile tests on CFRP coupons were carried out according to the ISO 527-5 (1997) recommendations. For the laminates and overlay epoxy adhesives, uniaxial tensile tests were performed complying with the procedures outlined by ISO 527 2 (1993). Further details related to the properties of the materials can be found in Bonaldo et al. (2006). All symbols are defined in the notation section.

\section{Strengthening Procedures}

When the concrete slabs attained, approximately, 28 days of age, the slits were opened in the strengthened slabs. The slits were filled with the epoxy adhesive using a spatula, and the CFRP laminates were then introduced into the slits. To ensure good adhesion between the new concrete overlay and the old concrete, the top surface of the last one was sandblasted to remove the cement laitance layer.

The SFRC overlay was bonded to the concrete slab sandblasted surface, using the epoxy adhesive with the properties indicated in Table 2. The bond product was spread over the substrate top surface with a spatula, and then the SFRC overlay was poured. A mini slipform was used to consolidate both the thin SFRC overlay and SFRC beam specimens. The mini slipform intends to simulate the real conditions of compaction of a thin SFRC overlay (Bonaldo et al. 2006). The manufacturers specifications and the ACI guidelines (ACI 503.2-92, ACI 503.5R-97 and ACI 503.6R-92) were followed to bond the fresh SFRC overlay to the hardened concrete.

\section{Results and Analysis}

\section{Load-displacement Response}

The load-mid span deflection curves of the tested slabs are presented in Fig. 4. The relationship between the displacements recorded in the other LVDTs and load are included elsewhere (Bonaldo et al. 2006). It can clearly be noticed in Fig. 4 that the experimental load-displacement curves of the unstrengthened and strengthened slabs have a typical trilinear diagram, which correspond to the following behavioral phases: the uncracked elastic; crack propagation with steel bars in elastic stage; steel reinforcement post-yielding stage. The unstrengthened control slabs behaved in a perfectly plastic manner in the post-yielding phase, whereas the strengthened slabs exhibited continuous hardening until maximum load. 
In the SL3S, SL4S, SL5SO and SL6SO slabs the width of the slits where the CFRP laminates were installed was of about $4.0 \mathrm{~mm}$. In the SL7SO and SL8SO slabs the width of the NSM slits was about $14.0 \mathrm{~mm}$ and $7.4 \mathrm{~mm}$, respectively. By examining the load-deflection curves in Fig. 4, it can be noticed that the width of the NSM slits had no influence on the deformational behavior of the slabs.

The cracking, yield and maximum loads, and the strength increasing ratio are given in Table 3 . In an experimental test, the cracking load is normally reported as a load corresponding to the occurrence of a crack for the first time. However, the cracking load is considered here as the load at which a significant change in the slope of the total load-deflection relationship is observed. The yield load is herein defined as the load which leads to a strain in the steel reinforcement that is equal to the yield strain measured from tension tests in coupons. A significant change in the slope of the total load-deflection curve is also observed in the vicinity of yield load. In Table 3 , the strength increasing ratio was calculated using the following expressions:

$$
\text { - CFRP strengthened slabs: } \frac{F_{u}^{C F R P}-F_{u}^{R E F}}{F_{u}^{R E F}}
$$

and

$$
\text { - CFRP \& SFRC strengthened slabs: } \frac{F_{u}^{C F R P \& S F R C}-F_{u}^{R E F}}{F_{u}^{R E F}} \text { and } \frac{F_{u}^{C F R P \& S F R C}-F_{u}^{C F R P}}{F_{u}^{C F R P}}
$$

where $F_{u}^{C F R P}, F_{u}^{R E F}$ and $F_{u}^{C F R P \& S F R C}$ are the average maximum load of CFRP strengthened slabs, reference slabs, and CFRP and SFRC overlay strengthened slabs, respectively.

The monitored strains at the mid-span, in the concrete top surface, steel bars and CFRP laminates are listed in Table 4. From the analysis of the strain values of Table 4, it can be concluded that, at the onset of the slabs' failure, the maximum strain in the CFRP ranged from $1.1 \%$ to $1.34 \%$, which is $60 \%$ to $73 \%$ of the CFRP laminate ultimate strain (see Table 2).

As expected, the concrete maximum compressive strain of the slabs only strengthened with CFRP laminates has exceeded $0.35 \%$, while in the hybrid strengthened slabs the concrete maximum compressive strain was below this value.

\section{Analytical Prediction of the Ultimate loads and Failure Modes}


Table 5 includes the theoretical calculations of the load capacity, the experimental loads at failure, the ultimate deflections and the failure modes of the tested slabs. Fig. 5 illustrates the internal strain and stress distribution for the CFRP strengthened cross section under flexure at the ultimate limit state, for the theoretical calculations of the resistant bending moment of a NSM strengthened RC cross section. In the calculations, the materials properties from Table 1 and Table 2 were assumed, together with the recommended values $\alpha=0.85$ and $\beta_{1}=0.72$, according to ACI 318-05, section 10.2.7.3. The same strain and stress distribution presented in Fig. 5 can be also used for the CFRP and SFRC strengthened cross sections, since the depth of the equivalent rectangular stress block remains in the SFRC layer.

Reference SL1 and SL2 slabs failed in flexure, i.e. by yielding of internal reinforcement, with extensive cracking in the tension flange, followed by concrete crushing at the top surface.

The SL3S and SL4S slabs, only strengthened with laminates, have also failed in flexure: yielding of the internal steel reinforcement followed by concrete crushing at the top surface. However, specimen SL3S failed in shear after significant deflection, by the formation of an intermediate shear crack mechanism.

In the combined strengthening case, for the other fours specimens with laminates and SFRC overlay, all slab strips failed in shear, by the formation of intermediate shear crack mechanism with extensive cracking in the tension flange.

The failure modes of the slabs strengthened only with laminates and strengthened with laminates and SFRC overlay are illustrated in Fig. 6.

In all the tested slabs strengthened by NSM technique, on the contrary to what has been commonly verified experimentally for the extensively studied EBR strengthening technique (Grace 2001, Smith and Teng 2002; Teng et al. 2003; Mosallam and Mosalam 2003; Ashour et al. 2004; Wu and Hemdan 2005), no premature CFRPdebonding occurred.

Early concrete cover delamination and plate-end failure, due to direct transverse tensile stress at the concrete cover-internal reinforcement interface and adhesive-concrete interface, respectively, are other common failure modes usually present in RC member strengthened with externally bonded FRP reinforcement (Ahmed et al. 2001; Smith and Teng 2002). Although this type of collapse has also been reported as a failure mechanism for the NSM strengthening technique (De Lorenzis and Nanni 2002; Rizkalla et al. 2003; El-Hacha and Rizkalla 2004; Hassan and Rizkalla 2004; Barros and Fortes 2005; Kotynia 2005), such occurrence was not observed in the present 
tests, even in the slab specimens having a concrete of low strength class (C20/25), a relative small distance between the NSM slits (about $70 \mathrm{~mm})$ and a high longitudinal equivalent reinforcement ratio, $\rho_{s, e q}\left(\rho_{s, e q}=1.08 \%\right.$ and $\rho_{s, e q}=0.71 \%$, for slabs strengthened with NSM and slabs strengthened with NSM and SFRC overlay, respectively). Here, the equivalent reinforcement ratio is defined as:

$$
\rho_{\mathrm{s}, e q}=\frac{A_{s}}{b \cdot d_{s}}+\frac{E_{f}}{E_{s}} \cdot \frac{A_{f}}{b \cdot d_{f}}
$$

where $b$ is the width of the slab section, $A_{s}, E_{s}$, and $d_{s}$ are the cross-sectional area, the Young's modulus, and the effective depth of the internal steel reinforcement, and $A_{f}, E_{f}$ and $d_{f}$, are the cross-sectional area, the Young's modulus and the effective depth of the laminates. However, more research about delamination is needed, taking into account variables such as the distance between the slits, the termination points of the NSM strengthening, the concrete strength, the percentage and arrangement of internal steel reinforcement, the effective reinforcement ratio and the ratio of CFRP strengthening with respect to the internal steel reinforcement $\left(A_{f} / A_{s}\right)$.

\section{Bond Stress between CFRP Laminates and Concrete}

Using the strains recorded in the strain gauges installed in the laminates, the average CFRP-concrete bond stresses developed along the CFRP laminates were evaluated. The average bond stress $\left(\tau_{b m}^{R L}\right)$ in a CFRP laminate, inbetween the strain gauges position, $\mathrm{SG}^{\mathrm{L}}$ (left) and $\mathrm{SG}^{\mathrm{R}}$ (right), was determined according to the following equation (refer to Fig. 7):

$$
\tau_{b m}^{R L}=\frac{E_{f} \cdot A_{f} \cdot \Delta \varepsilon^{R L}}{2 \cdot w_{f} \cdot L^{R L}}(\mathrm{MPa})
$$

where $L^{R L}$ is the distance between two consecutive strain gauges; $\Delta \varepsilon^{R L}$ is the axial strain difference between the strain gauge at right and left sections; and $w_{f}$ is the width of the CFRP laminate, respectively. In this approach, constant bond stress between the strain gauges $\mathrm{SG}^{\mathrm{L}}$ and $\mathrm{SG}^{\mathrm{R}}$ is assumed. The $\tau_{b m}^{R L}$ variation during the loading 
process of the SL4S and SL6SO slabs is shown in Fig. 8, which is typical of the $\tau_{b m}^{R L}$ variation observed in the remaining slabs strengthened with NSM technique (Bonaldo et al. 2006).

Fig. 8 shows that, as expected, up to concrete cracking the strain in the CFRP laminates is very low. In general, a low bond stress profile is also developed at laminate-epoxy interfaces, at the serviceability limit deflection, since the average bond stress computed at this deflection level $(7.2 \mathrm{~mm}$ at mid-span) was below to 1.0 MPa. It can also be noticed that the bond stress was below $6.5 \mathrm{MPa}$ at the ultimate load. When the longitudinal bars started yielding, an abrupt increase of bond stress occurred between SG6 and SG7 since the maximum bending moment occurs at the slab cross-section where SG7 is located and the laminates need to support the load increment applied to the slab. In general, a shear crack was formed between SG5 and SG6. After the formation of this crack, the bond stress between these two SG increased abruptly, followed by a significant decrease of the bond stress between SG6 and SG7. These two opposite tendencies of the bond stress in these two regions remained up to the failure of the slab. However, the maximum $\tau_{b m}^{R L}$ was considerably lower than the average bond stress $\left(\tau_{b m}=12 \mathrm{MPa}\right)$ obtained in pullout-bending tests carried out to assess the bond stress-slip relationship for the NSM technique (Sena-Cruz and Barros 2004a, b; Sena-Cruz 2004). This indicates that the bond length of the laminate, at each side of the shear failure crack formed in the tested slabs, was sufficiently high to preclude considerable slip.

\section{Crack Spacing Analysis}

The distinct crack feature of reference and strengthened slabs, shown in Fig. 9, clearly reveals the significant improvement in the crack behavior provided by the used strengthening strategies.

The expression from the FIB (2001) was considered herein to calculate the theoretical average crack spacing for the tested slab strips. The average crack spacing, experimentally measured after the slabs have been tested, was determined as schematically described in Fig. 10 (Bonaldo et al. 2006).

According to FIB (2001), assuming stabilized cracking, the mean crack spacing, $s_{r m}$, taking into account the effect of both the internal reinforcement and external strengthening (EBR), can be calculated as: 


$$
s_{r m}=\frac{2 \cdot f_{c t m} \cdot A_{c, e f f}}{\tau_{s m} \cdot u_{s}} \cdot \frac{E_{s} \cdot A_{s}}{E_{s} \cdot A_{s}+\xi_{b} \cdot E_{f} \cdot A_{f}}
$$

where $\xi_{b}=\frac{\tau_{f m} \cdot E_{s} \cdot \phi_{s} \cdot u_{f}}{\tau_{s m} \cdot E_{f} \cdot 4 \cdot A_{f}} ; A_{c, \text { eff }}$ is the effective area of concrete in tension, the area of concrete surrounding the tension reinforcement; $u_{s}$ is the bond perimeter of the internal steel reinforcement; $\tau_{s m}=1.8 \cdot f_{c t m}$ is the average bond stress of the steel (CEB-FIP 1993); $\tau_{f m}$ is the average bond stress of the CFRP strengthening: $\tau_{f m}=1.25 \cdot f_{c t m}$ for EBR (FIB 2001) and $\tau_{f m}=1.85 \cdot f_{c t m}$ is used in the present work for NSM. The coefficient of 1.85 for calculating the value of $\tau_{f m}$ was determined through an inverse analysis of bond stress between SG7 and SG6 when the intermediate shear crack was formed (see the section "Bond Stress between CFRP Laminates and Concrete", above); $u_{f}$ is the bond perimeter of the CFRP strengthening for EBR (FIB 2001). Here, in the NSM context, $u_{f}$ is considered as the perimeter length of the cross-section of the failure plane, which is assumed being $1.0 \mathrm{~mm}$ offset from the NSM laminate (CIDAR 2006): $u_{f}=n_{f} \cdot\left[\left(t_{f}+2\right)+2 \cdot\left(w_{f}+1\right)\right], n_{f}$ is the number of NSM CFRP laminates; $\phi_{s}$ is the mean bar diameter of the internal steel reinforcement; $E_{s}$ is the modulus of elasticity of the steel reinforcement; $w_{f}$ is the width of the CFRP laminate; $t_{f}$ is the thickness of the CFRP laminate, and $E_{f}$ is the modulus of elasticity of the CFRP laminate.

The results indicated in Table 6 show that, the enhancements introduced in the FIB formulation (FIB 2001), have allowed a good prediction of the crack spacing measured experimentally.

\section{Ductility Analysis}

In strengthening of RC structures with EBR it is notable that the increase in strength and stiffness is sometimes attained at the expense of a loss in ductility, or loss of capacity of the structures to deflect inelastically while sustaining a significant percentage of its maximum load. Ductility is an important property for safe design of strengthening of any structural element. As NSM strengthening with CFRP is a relative recent strengthening strategy, understanding the effect of this technique on the ductility of a RC member is crucial. A method, based on the ductility index commonly used, is considered herein to analyze the ductility of the slabs. 
Ductility of RC members has generally been measured by parameters designed as bending ductility indexes. In the present work, the ductility indexes are expressed as the ratio between the deflection, or curvature, at an ultimate condition $\left(\Delta_{u}\right.$ and $\chi_{u}$, respectively) and the deflection, or curvature, at the yield load $\left(\Delta_{y}\right.$ and $\chi_{y}$, respectively), as follows:

$$
\mu_{\Delta}=\frac{\Delta_{u}}{\Delta_{y}}
$$

and

$$
\mu_{\chi}=\frac{\chi_{u}}{\chi_{y}}
$$

The deflection at ultimate condition is the one recorded when a compressive strain of $0.3 \%$ was attained in the slab top surface, since it is the average of the strain at concrete compressive strength (about $0.25 \%$ ) and the strain corresponding to concrete crushing $(0.35 \%)$ according to CEB-FIP (1993). Table 7 lists the values of the ductility indexes for each of the slabs, as well as, the average values of these indexes for the unstrengthened and strengthened slabs. By examining Table 7, a decrease of about $42 \%$ in the average values of $\mu_{\Delta}$ index for the NSM strengthened slabs is noticed, if $\mu_{\Delta}$ of the reference slabs is used for comparison purposes. As aforementioned, the deformational capability of the slabs strengthened using NSM was limited by concrete crushing in the extreme compressive fibers. Furthermore, no significant changing in the ductility index of the slabs strengthened using NSM and SFRC overlay, with respect to the unstrengthened control slabs, was observed. In the slabs strengthened with the hybrid system, the increase in the energy absorption capacity at the compression softening phase, provided by the fiber reinforcement mechanisms, avoided the SFRC overlay to crush. However, the deformability of these slabs was limited by the shear failure.

According to the FIB (2001) recommendations, the minimum ductility index, in terms of curvature, should be approximately 1.7 and 2.6 for concrete types C35/45 or lower and concrete types higher than C35/45, respectively. The ductility index should exceed this minimum value to prevent the occurrence of sudden failure in the strengthened flexural members. The minimum acceptable ductility index ensures that the internal reinforcement experiences plastic deformation in order to provide the desired warning prior to failure of the member. 
The enhanced bond condition provides a much more ductile behavior for the NSM strengthening technique comparatively to the EBR strengthening technique and the bond ductility when the composite material is applied into slits is comparable to the bond ductility of embedded steel rebars.

\section{Conclusions}

An experimental program was conducted in order to: (a) investigate the NSM strengthening technique for reinforced concrete slabs, and (b) evaluate structural performance of a hybrid strengthening technique for RC slabs, composed of CFRP laminates on the tensile surface and SFRC overlay on the top compressive surface. For this purpose a total of eight slabs were tested. The following conclusions can be drawn from this study:

- The carried out experimental program demonstrated that the hybrid strengthening technique has great potential application towards flexural strengthening of RC slabs, not only in terms of increasing the slab ultimate load capacity, but also its stiffness;

- Using for comparison purposes the RC slabs of $1.8 \mathrm{~m}$ span length, with a steel reinforcement ratio of $0.63 \%$, it was verified that a CFRP strengthening ratio of $0.25 \%\left(A_{f} / A_{s} \approx 40 \%\right)$ increased the service load in about $55 \%$. The slabs strengthened by NSM technique and SFRC presented an increase of approximately $244 \%$ in the service load with respect to that of the reference slabs. Comparatively to the NSM technique, the hybrid strengthening strategy led to an increase of about $122 \%$ in the load at the deflection serviceability limit state;

- The hybrid strengthening system also led to an increase of about $350 \%$ in the RC slab maximum load carrying capacity with respect to that of the reference slabs, and an increase of about $80 \%$ in comparison to that of the slabs only strengthened with NSM technique. When compared to the reference slabs, an increase of about $150 \%$ was obtained for the load carrying capacity when applying the NSM strengthening technique;

- The concrete cracking spacing measured at the bottom of the slabs' lateral face indicates that NSM technique provides a significant improvement in the crack behavior of RC slabs. In the obtained results, the average crack spacing $\left(s_{r m}\right)$ of the lightly reinforced concrete slabs strengthened with NSM was about $45 \%$ lower the $s_{r m}$ measured in the reference slabs. A reduction of about $36 \%$ in the $s_{r m}$ was observed in the hybrid strengthened slabs;

- For the stabilized cracking phase and taking into account appropriate considerations for the NSM strengthening 
system, the average crack spacing of the strengthened slabs may be achieved with acceptable accuracy using the analytical expression suggested by FIB (2001);

- When compared to the bond strength recorded in pullout-bending tests, a very low bond stress profile was observed through the CFRP laminate-epoxy adhesive interface along the laminates;

- The ductility index for slabs strengthened with NSM system and SFRC overlay, based on deflections measurements, was the same of the reference slabs. The slabs strengthened only with NSM laminates had a ductility index $42 \%$ lower than the reference slabs. This reduction in ductility is attributed to the low resistance of the concrete, since early compressive failure was observed at the top surface of the slabs;

- The NSM strengthening system has also provided a significant increase in the stiffness and deformability, consistent with the high stress redistribution (closely spaced crack pattern) owing to the prominent composite action between the CFRP reinforcement and concrete. Since the hybrid strengthening system led to substantial increase in the flexural resistance, the shear capacity of the composite slabs limited their deformability; however, the stiffness of the slabs increased significantly and the ductility level maintained; and

- The SFRC overlay bonding procedures can be considered adequate, since no slip was observed, the connection between SFRC overlay and the RC slab was able to transfer horizontal shear stress, forming consequently a monolithic flexural cross-section.

\section{Acknowledgments}

The authors acknowledge the financial support of the Portuguese Science and Technology Foundation (FCT), PhD grant number SFRH / BD / 11232 / 2002. Thanks also for the companies "Companhia Geral de Cal e Cimento S.A. (SECIL)", Sika S.A., "Central do Pego", "Pedreiras Bezerras", Bekaert NV, "Degussa Construction Chemicals Portugal S.A.”, S\& $\mathrm{P}^{\circledR}$ Reinforcement, which generously have supplied cement; overlay bond product; fly ash; aggregates; steel fibers; superplasticizer and CFRP adhesive; and CFRP laminate, respectively.

\section{Notation}

The following symbols are used in this paper: 


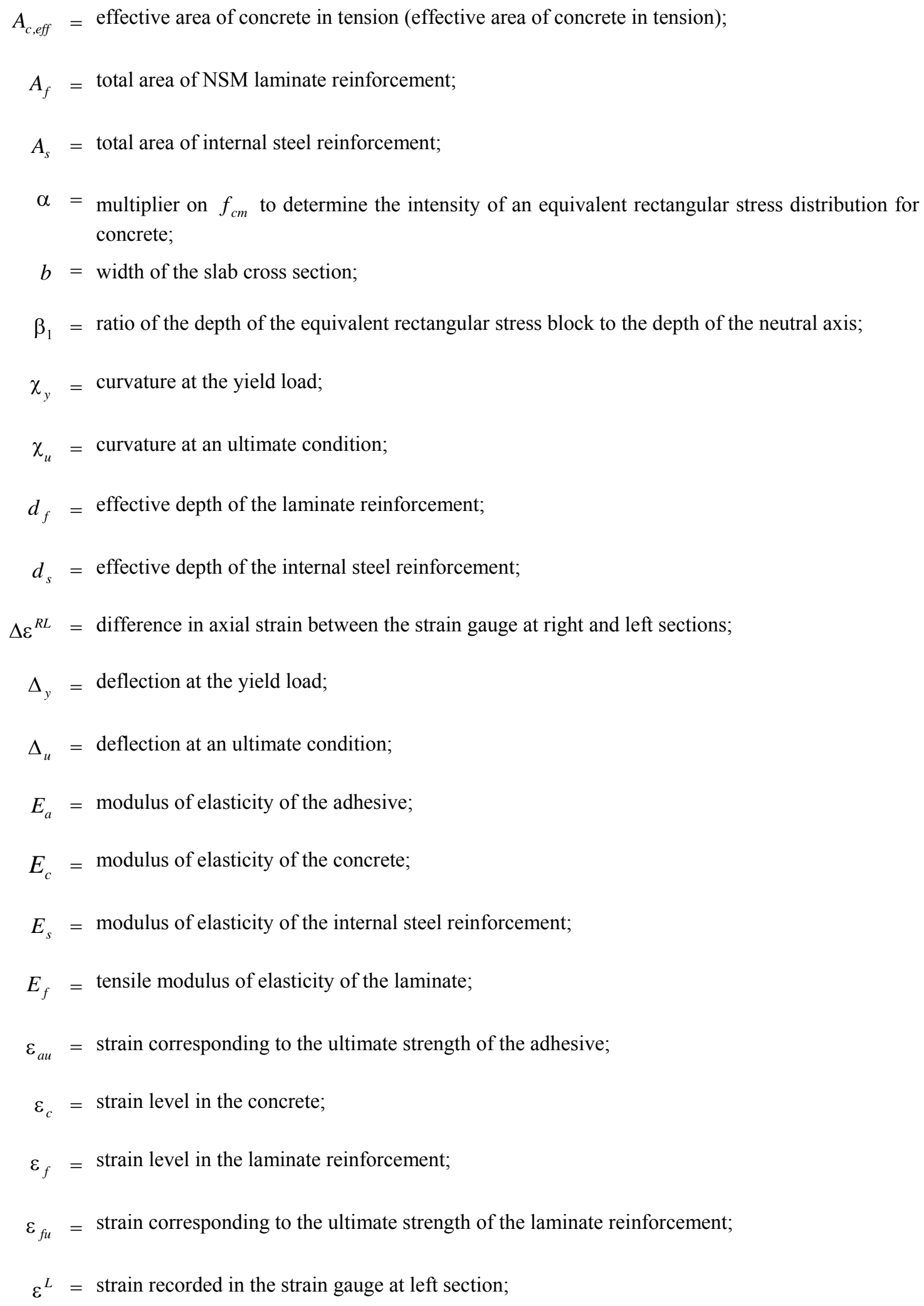




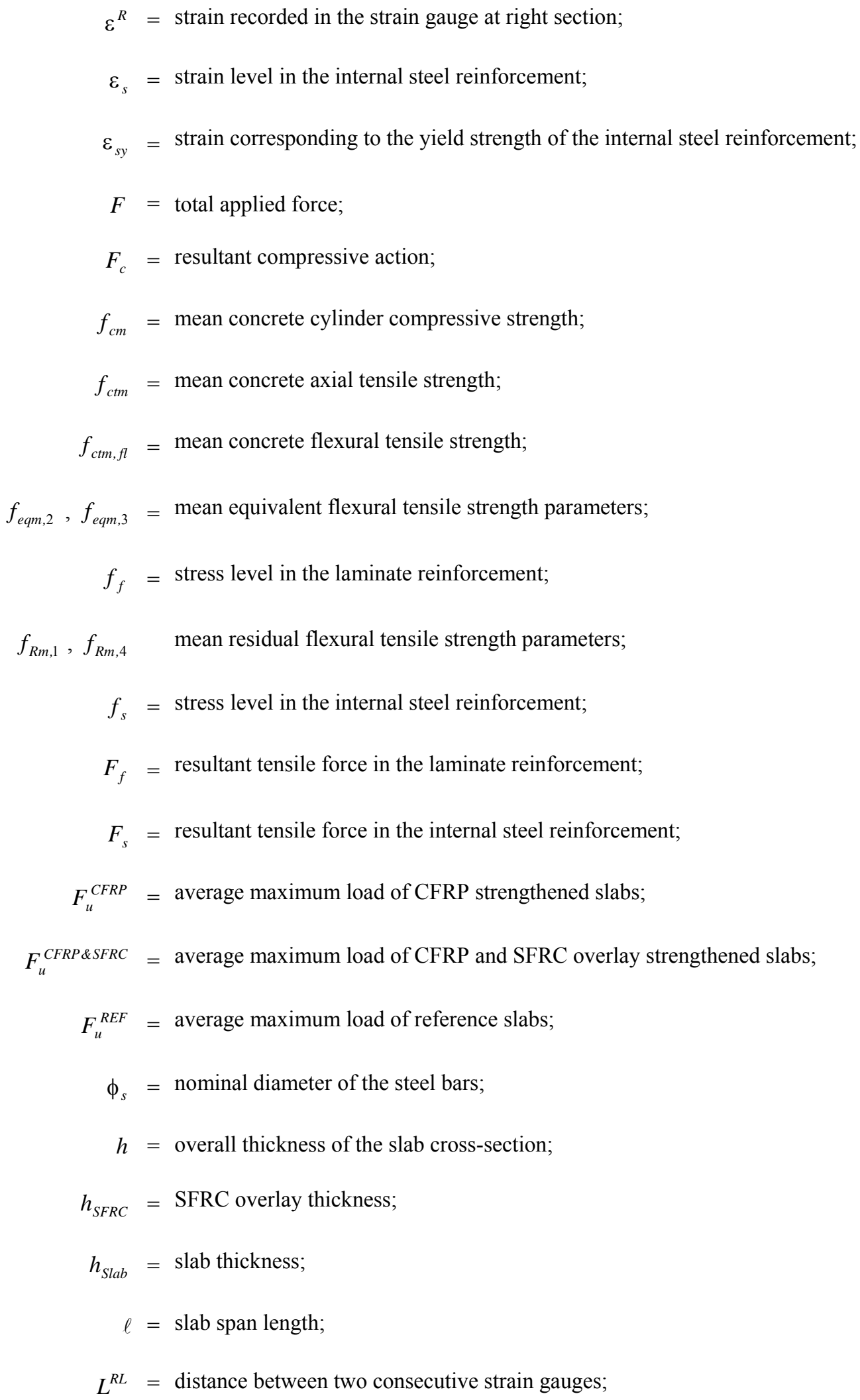




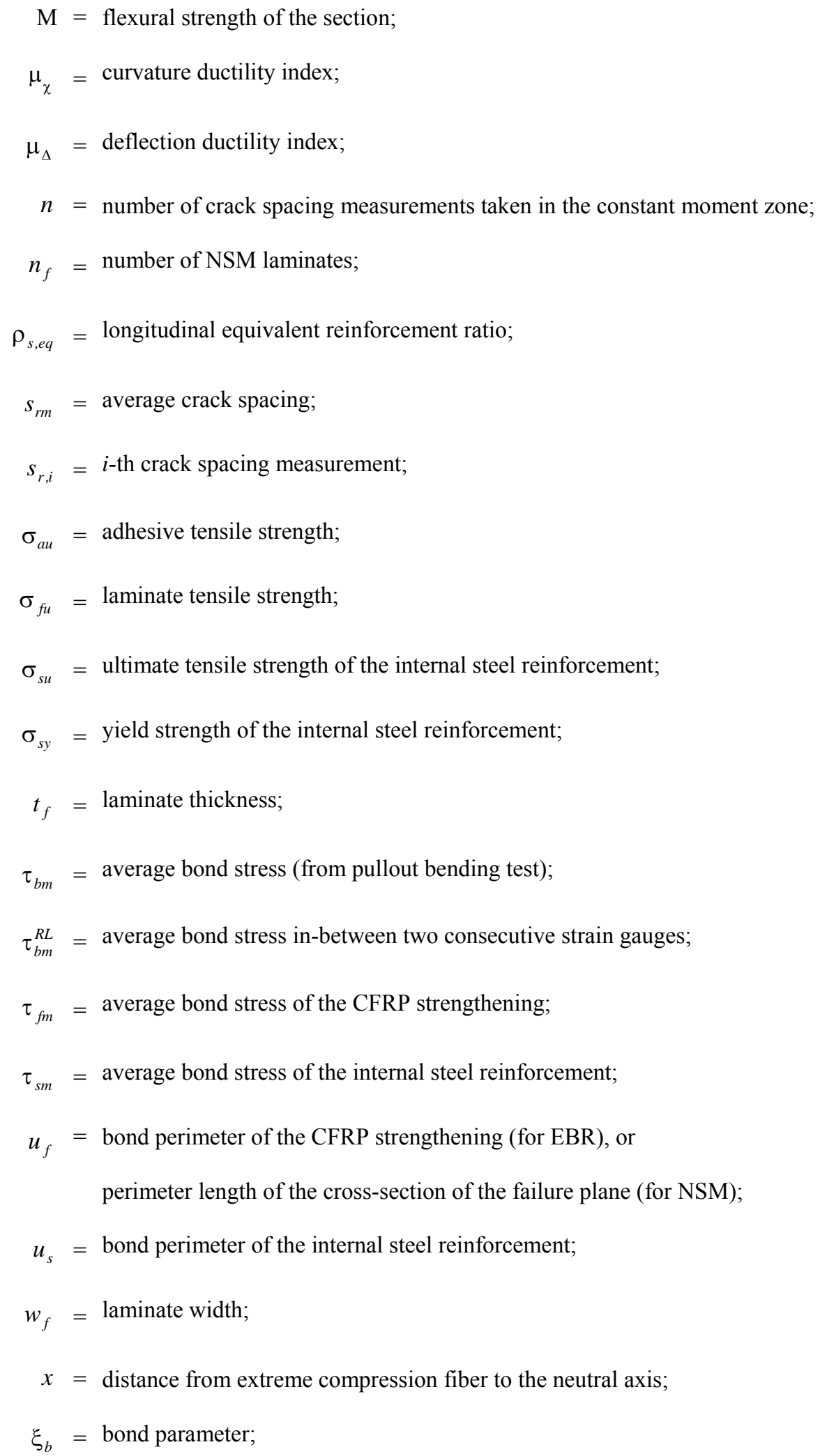




\section{References}

Ahmed, O., Gemert, D. V., and Vandewalle, L. (2001). "Improved model for plate-end shear of CFRP strengthened RC beams." Cem. Concr. Compos., 23(1), 3-19.

American Concrete Institute (ACI). (1992). "Guide for the application of epoxy and latex adhesives for bonding freshly mixed and hardened concretes.” ACI 503.6R-92, Detroit, pp. 4.

American Concrete Institute (ACI). (1992). "Standard specification for bonding plastic concrete to hardened concrete with a multi-component epoxy adhesive.” ACI 503.2-92 (Reapproved 1997), Detroit, pp. 5.

American Concrete Institute (ACI). (1997). "Guide for the selection of polymer adhesives with concrete." ACI 503.5R-97, Detroit, pp. 4.

American Concrete Institute (ACI). (2005). "Building code requirements for structural concrete and commentary." ACI 318-05, Detroit, pp. 430.

Ashour, A. F., El-Refaie, S. A., and Garrity, S. W. (2004). "Flexural strengthening of RC continuous beams using CFRP laminates.” Cem. Concr. Compos., 26 (7), 765-775.

Barros, J. A. O., and Dias, S. J. E. (2006). "Near surface mounted CFRP laminates for shear strengthening of concrete beams." Cem. Concr. Compos., 28(3), 276-292.

Barros, J. A. O., and Fortes, A. S. (2005). "Flexural strengthening of concrete beams with CFRP laminates bonded into slits.” Cem. Concr. Compos., 27(4), 471-480.

Barros, J. A. O., and Sena-Cruz, J. M. (2001). "Strengthening a prestressed concrete slab by epoxy-bonded FRP composites and SFRC overlayer.” Proc., 7th Int. Conf. on Inspection, Appraisal, Repairs and Maintenance of Buildings and Structures, Nottingham Trent University, United Kingdom, 211-218.

Barros, J. A. O., Cunha, V. M. C. F., Ribeiro, A. F., and Antunes, J. A. B. (2005). "Post-Cracking Behaviour of Steel Fibre Reinforced Concrete.” Mater. Struct., 38(275), 47-56.

Barros, J. A. O., Ferreira, Fortes, A. S., and Dias, S. J. E. (2006). “Assessing the effectiveness of embedding CFRP laminates in the near surface for structural strengthening." Constr. Build. Mater., 20(7), 478-491.

Blaschko, M., and Zilch, K. (1999). "Rehabilitation of concrete structures with CFRP strips glued into slits." Proc., 12th Int. Conf. on Composite Materials, Organization of the Int. Conf. on Composite Materials, Paris, CD-ROM, pp. 7.

Bonaldo, E., Castro-Gomes, J. P., Barros, J. A. O., and Lourenço, P. B. (2005a). "SEM analysis of bond epoxy 
based layer between hardened concrete and SFRC repairing." Proc., 10th Euroseminar on Microscopy Applied to Building Materials - EMABM, University of Paisley, Scotland, pp. 15.

Bonaldo, E., Barros, J. A. O., and Lourenço, P. B. (2005b). "Bond characterization between concrete substrate and repairing SFRC using pull-off testing." Int. J. Adhes. Adhes., 25(6), 463-474.

Bonaldo, E., Barros, J. A. O., and Lourenço, P. B. (2006). "Efficient strengthening technique to increase the flexural resistance of existing RC slabs: NSM CFRP laminates and compressive thin bonded SFRC overlay." Rep. No. 09-DEC/E-06, Department of Civil Engineering, University of Minho, $<$ http://www.civil.uminho.pt/composites>, pp. 118.

Carolin, A. (2003). "Carbon fibre reinforced polymers for strengthening of structural elements." Doctoral thesis, Division of Structural Engineering, Luleå University of Technology, Sweden, pp. 190.

CEB-FIP model code 1990. (1990). Thomas Telford, London, pp. 437.

Centre for Infrastructure Diagnosis, Assessment and Rehabilitation (CIDAR). (2006). "Design Guideline for RC structures retrofitted with FRP and metal plates: beams and slabs.” DRAFT 3, Submitted to Standards Australia 02/02/06, The University of Adelaide <http://www.civeng.adelaide.edu.au/index.html> (March 8, 2006), pp. 109.

De Lorenzis, L., and Nanni, A. (2001). "Shear strengthening of reinforced concrete beams with near-surface mounted fibre reinforced polymer rods.” ACI Struct. J., 98(1), 60-68.

De Lorenzis, L., and Nanni, A. (2002). "Bond between near surface mounted FRP rods and concrete in structural strengthening." ACI Struct. J., 99(2), 123-133.

El-Hacha, R., and Rizkalla, S. H. (2004). "Near surface mounted FRP reinforcements for flexural strengthening of concrete structures.” ACI Struct. J., 101(5), 717-726.

Eurocode 2. (2004). "Eurocode 2: Design of concrete structures, EN 1992-1-1." European Committee for Standardization, Brussels, Belgium, pp. 225.

Fédération Internationale du Béton (FIB). (2001). "Externally bonded FRP reinforcement for RC structures." Bulletin 14, Lausanne, Switzerland, pp. 138.

Grace, N. F. (2001). "Strengthening of negative moment region of reinforced concrete beams using carbon fiberreinforced polymer strips.” ACI Struct. J., 98(3), 347-358.

Hassan, T. K. and Rizkalla, S. H. (2004). "Bond mechanism of NSM FRP bars for flexural strengthening of concrete structures." ACI Struct. J., 101(6), 830-839. 
ISO 527-2 (1993). "Plastics - Determination of tensile properties - Part 2: Test conditions for moulding and extrusion plastics.” International Organization for Standardization (ISO), Geneva, Switzerland, pp. 5.

ISO 527-5 (1997). "Plastics - Determination of tensile properties - Part 5: Test conditions for unidirectional fibrereinforced plastic composites." International Organization for Standardization (ISO), Geneva, Switzerland, pp. 9.

Jung, W. -T., Park, Y. -H., Park, J. -S, Kang, J. -Y, and You, Y. -J. (2005). "Experimental investigation on flexural behavior of RC beams strengthened by NSM CFRP reinforcements." Proc., 7th Int. Symposium, FiberReinforced (FRP) Polymer Reinforcement for Concrete Structures - FRPRCS-7, C. K. Shield, J. P. Busel, S. L. Walkup, and D. D. Gremel, eds., SP-230, American Concrete Institute, Farmington Hills, Mich, 795-806.

Kotynia, R. (2005). "Strengthening of reinforced concrete structures with near surface mounted FRP reinforcement." Proc., 5th International Conference - Analytical Models and New Concepts in Concrete and Masonry Structures AMCM 2005, Gliwice - Ustroń, pp. 8.

Liu, I. S. T., Oehlers, D. J., and Seracino, R. (2006). "Tests on the ductility of reinforced concrete beams retrofitted with FRP and steel near-surface mounted plates.” J. Compos. Constr., 10(2), 106-114.

Mosallam, A. S., and Mosalam, K. M. (2003). "Strengthening of two-way concrete slabs with FRP composite laminates.” Constr. Build. Mater., 17(1), 43-54.

NP-EN 10 002-1 (1990). "Metallic materials - Tensile testing. Part 1: Method of test (at ambient temperature)." European Standard, CEN, Brussels, Belgium, pp. 35.

NP-EN 12 390-3 (2002). "Testing hardened concrete - Part 3: Compressive strength of test specimens." European Standard, CEN, Brussels, Belgium, pp. 18.

RILEM. (1985). "FMC1 - Determination of the fracture energy of mortar and concrete by means of three-point bend tests on notched beams.” Mater. Struct., 18(106), 285-290.

RILEM. (1994). "Modulus of elasticity of concrete in compression, Technical recommendations for the testing and use of construction materials." Technical Committee CPC8, 25-27.

RILEM. (2002). “Technical Committee 162-TDF - Test and design methods for steel fibre reinforced concrete. Final Recommendation.” Mater. Struct., 35, 579-582.

Rizkalla, S. H., Hassan, T. K. and Hassan, N. (2003). "Design recommendations for the use of FRP for reinforcement and strengthening of concrete structures.” J. Prog. Struct. Engng Mater., 5(1), 16-28. 
Sena-Cruz, J. M. (2004). "Strengthening of concrete structures with near-surface mounted CFRP laminate strips." PhD Thesis, Department of Civil Engineering, University of Minho, <http://www.civil.uminho.pt/composites> (July 4, 2005), pp. 198.

Sena-Cruz, J. M., and Barros, J. A. O. (2004a). "Modeling of bond between near-surface mounted CFRP laminate strips and concrete." Comput. Struct., 82(17-19), 1513-1521.

Sena-Cruz, J. M., and Barros, J. A. O. (2004b). "Bond between near-surface mounted CFRP laminate strips and concrete in structural strengthening." J. Compos. Constr., 8(6), 519-527.

Smith, S. T. and Teng, J. G. (2002). "FRP-strengthened RC beams. I: review of debonding strength models." Eng. Struct., 24(4), 385-395.

Teng, J. G., Smith, S. T., Yao, J., and Chen, J. F. (2003). "Intermediate crack-induced debonding in RC beams and slabs." Constr. Build. Mater., 17(6-7), 447-462.

Walser, R., and Steiner, W. (1997). "Strengthening a bridge with advanced materials." Struct. Engrg. Int. (IABSE), 2(7), 110-112.

Wu, Z., and Hemdan, S. (2005). "Debonding in FRP-strengthened flexural members with different shear-span ratios.", Proc., 7th International Symposium on Fiber-Reinforced (FRP) Polymer Reinforcement for Concrete Structures (FRPRCS-7), ACI, SP 230-24, Kansas City, Missouri, 411-426. 


\section{TABLE CAPTIONS}

Table 1. Characteristics of the Plain Concrete

Table 2. Summary of the Characteristics of the Steel Reinforcement, CFRP and its Adhesive, and SFRC and its Adhesive

Table 3. Summary of the Results in Terms of Loads

Table 4. Summary of the Monitored Strains

Table 5. Theoretical Calculations Compared with Loads at Failure, Ultimate Deflection and Mode of Failure

Table 6. Experimental and Analytical Crack Spacing

Table 7. Ductility Ratios of the Slab Specimens Tested 
Table 1. Characteristics of the Plain Concrete

\begin{tabular}{|c|c|c|c|c|c|}
\hline \multirow{2}{*}{ Mix } & \multirow{2}{*}{ Slab } & \multicolumn{2}{|l|}{ Property } & \multirow[b]{2}{*}{$f_{c t m}{ }^{\mathrm{a}}(\mathrm{MPa})$} & \multirow[b]{2}{*}{$E_{c}(\mathrm{GPa})$} \\
\hline & & $f_{c m}(\mathrm{MPa})$ & $f_{c t m, f l}(\mathrm{MPa})$ & & \\
\hline \multirow{4}{*}{ B1 } & $\mathrm{SL}^{\mathrm{b}}$ & & & & \\
\hline & SL4S & 25.97 & 2.91 & 1.39 & 27.69 \\
\hline & SL6SO $^{d}$ & $(2.16 \%)$ & $(20.87 \%)$ & (20.64\%) & $(6.80 \%)$ \\
\hline & $\mathrm{SL}_{7 \mathrm{SO}^{\mathrm{d}}}$ & & & & \\
\hline \multirow{4}{*}{ B2 } & $\mathrm{SL} 2^{\mathrm{b}}$ & & & & \\
\hline & SL3S $S^{c}$ & 26.35 & 3.26 & 1.56 & 26.61 \\
\hline & $\mathrm{SL} \mathrm{SO}^{\mathrm{d}}$ & $(3.36 \%)$ & $(26.19 \%)$ & $(25.75 \%)$ & $(6.13 \%)$ \\
\hline & $\mathrm{SL8SO}^{\mathrm{d}}$ & & & & \\
\hline
\end{tabular}

(value) Coefficient of Variation $(\mathrm{COV})=($ Standard deviation/Average $) \times 100 ;{ }^{a}$ Derived from CEB-FIP (1993);

${ }^{\mathrm{b}}$ Control slabs; ${ }^{\mathrm{c}}$ NSM strengthened slabs; ${ }^{\mathrm{d}}$ NSM and SFRC strengthened slabs. 
Table 2. Summary of the Characteristics of the Steel Reinforcement, CFRP and its Adhesive, and SFRC and its Adhesive

\begin{tabular}{|c|c|c|c|c|}
\hline Steel reinforcement & CFRP laminate $^{\mathrm{a}}$ & Laminate adhesive & SFRC overlay & Overlay adhesive \\
\hline$\phi_{s}=8 \mathrm{~mm}$ & $t_{f}=1.41 \mathrm{~mm}$ & & $\begin{array}{l}f_{c m}=43.23 \mathrm{MPa} \\
E_{c}=30.08 \mathrm{GPa}\end{array}$ & \\
\hline$E_{s}=200.32 \mathrm{GPa}$ & $w_{f}=9.37 \mathrm{~mm}$ & $E_{a}=7.47 \mathrm{GPa}$ & $f_{e q m, 2}=4.31 \mathrm{MPa}$ & $E_{a}=3.62 \mathrm{GPa}$ \\
\hline$\sigma_{s y}=465.75 \mathrm{MPa}$ & $E_{f}=156.10 \mathrm{GPa}$ & $\sigma_{a u}=33.03 \mathrm{MPa}$ & $f_{\text {eqm }, 3}=3.47 \mathrm{MPa}$ & $\sigma_{a u}=26.56 \mathrm{MPa}$ \\
\hline$\varepsilon_{s y}=0.25 \%$ & $\sigma_{f u}=2879.13 \mathrm{MPa}$ & $\varepsilon_{a u}=0.48 \%$ & $f_{R m, 1}=4.45 \mathrm{MPa}$ & $\varepsilon_{a u}=1.07 \%$ \\
\hline$\sigma_{s u}=557.12 \mathrm{MPa}$ & $\varepsilon_{f u}=1.85 \%$ & & $f_{R m, 4}=2.24 \mathrm{MPa}$ & \\
\hline
\end{tabular}

\footnotetext{
${ }^{a}$ Pultruded CFRP laminate provided by the $\mathrm{S} \& \mathrm{P}^{(\mathbb{R}}$ company.
} 
Table 3. Summary of the Results in Terms of Loads and Deflections

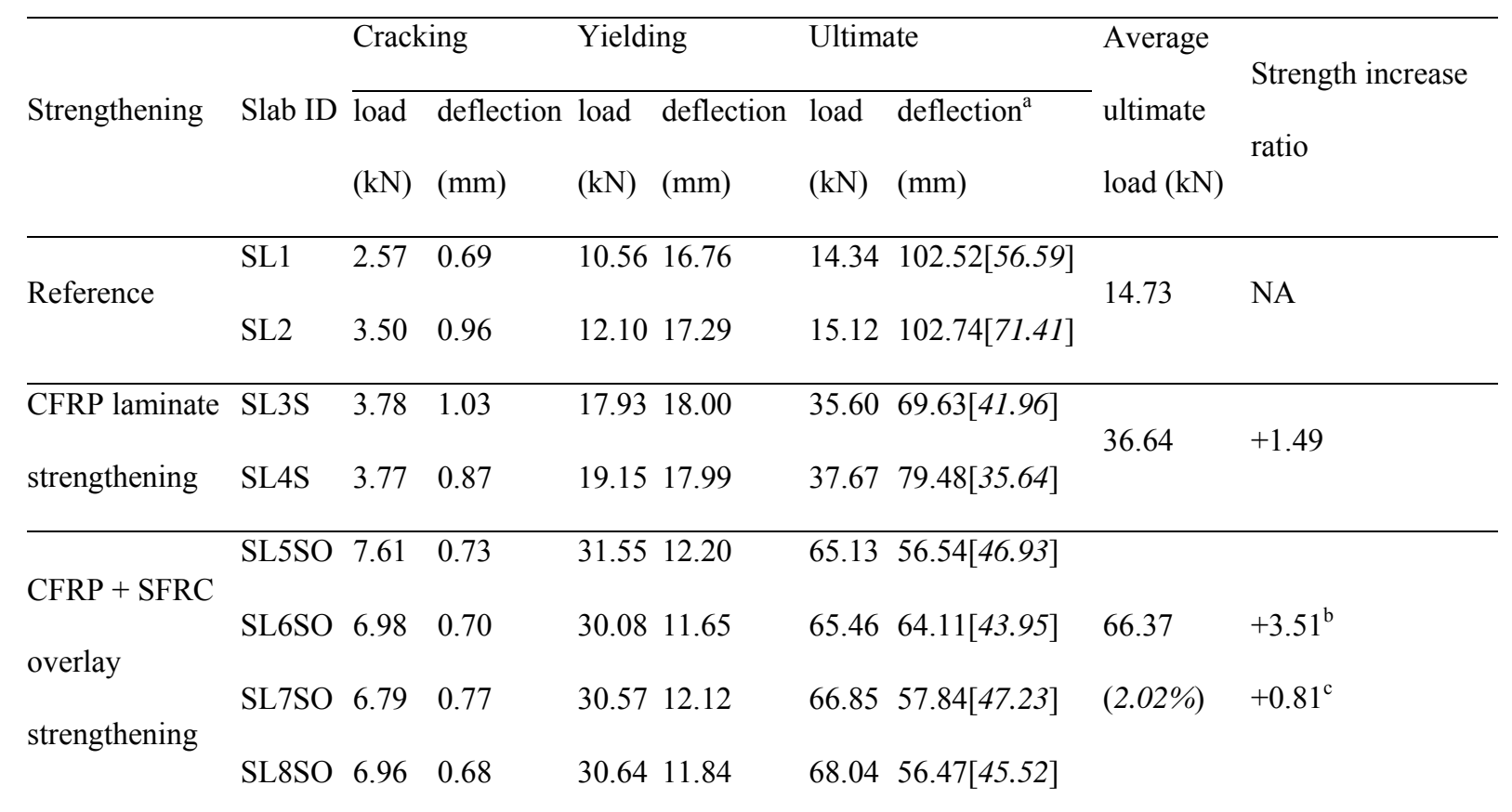

(value) Coefficient of Variation $(\mathrm{COV})=($ Standard deviation/Average $) \times 100 ;{ }^{\text {a }}$ Deflection registered at ultimate load in strengthened slabs; The deflection in brackets is the deflection corresponding to a concrete compressive strain of $0.3 \%$ in the strain gauges on top of slab; ${ }^{b}$ With respect to the reference slabs; ${ }^{c}$ With respect to the CFRP laminate strengthened slabs; NA: not applicable. 
Table 4. Summary of the Monitored Strains

\begin{tabular}{|c|c|c|c|c|}
\hline \multirow[b]{2}{*}{ Strengthening } & \multirow[b]{2}{*}{ Slab } & \multicolumn{2}{|c|}{ Concrete compressive } & \multirow{2}{*}{$\begin{array}{l}\text { CFRP laminate strain } \\
(\%)\end{array}$} \\
\hline & & $\operatorname{strain}^{\mathrm{a}}(\%)$ & Steel strain ${ }^{\mathrm{b}}(\%)$ & \\
\hline \multirow{2}{*}{ Reference } & SL1 & $0.36[14.05]^{\mathrm{d}}$ & $0.84[14.00]$ & NA \\
\hline & SL2 & $0.31[14.56]$ & 1.99 [14.89] & NA \\
\hline CFRP laminate & SL3S & 0.47 [35.49] & $\mathrm{NE}$ & $1.11[35.58]$ \\
\hline strengthening & SL4S & 0.51 [34.39] & $2.08[25.07]$ & $1.25[36.91]$ \\
\hline \multirow{2}{*}{$\mathrm{CFRP}+\mathrm{SFRC}$} & SL5SO & 0.34 [65.13] & $2.09[39.20]$ & 1.34 [65.13] \\
\hline & SL6SO & $0.34[65.24]$ & $0.75[44.84]$ & $1.22[65.46]$ \\
\hline overlay & SL7SO & $0.28[60.61]$ & $2.15[41.87]$ & $1.31[66.85]$ \\
\hline strengthening & SL8SO & $0.35[67.62]$ & $1.21[45.64]$ & $1.34[68.04]$ \\
\hline
\end{tabular}

[value] Corresponding load in brackets; ${ }^{a}$ Maximum value of SG9 and SG10; ${ }^{b}$ Maximum value of SG1, SG2 and SG3; ${ }^{\mathrm{c}}$ Maximum value recorded in SG7 and SG8; ${ }^{\mathrm{d}}$ The load in brackets is the maximum load; NA: not applicable; NE: not evaluated. 
Table 5. Theoretical Calculations Compared with Loads at Failure, Ultimate Deflection and Mode of Failure

\begin{tabular}{|c|c|c|c|c|c|c|}
\hline \multirow[b]{2}{*}{ Strengthening } & \multirow[b]{2}{*}{ Slab } & \multirow[b]{2}{*}{$\begin{array}{l}\text { Calculated } \\
\text { load }(\mathrm{kN})\end{array}$} & \multirow[b]{2}{*}{$\begin{array}{l}\text { Experimental } \\
\text { load }(\mathrm{kN})\end{array}$} & \multirow[b]{2}{*}{$\begin{array}{l}\text { Experimental/ } \\
\text { calculated } \\
\text { ratio }\end{array}$} & \multirow[b]{2}{*}{$\begin{array}{l}\text { Ultimate } \\
\text { deflection }^{\mathrm{a}} \\
(\mathrm{mm})\end{array}$} & \multirow[b]{2}{*}{$\begin{array}{l}\text { Type of } \\
\text { failure }\end{array}$} \\
\hline & & & & & & \\
\hline \multirow{2}{*}{ Reference } & SL1 & 13.84 & 14.34 & 1.04 & 102.52 & Flexure \\
\hline & SL2 & 14.01 & 15.12 & 1.08 & 102.74 & Flexure \\
\hline CFRP laminate & SL3S & 37.58 & 35.60 & 0.95 & 69.63 & Flexure $^{b}$ \\
\hline strengthening & SL4S & 37.58 & 37.67 & 1.00 & 79.48 & Flexure \\
\hline \multirow{2}{*}{$\mathrm{CFRP}+\mathrm{SFRC}$} & SL5SO & 66.90 & 65.13 & 0.97 & 56.54 & Flexo-shear $^{\mathrm{c}}$ \\
\hline & SL6SO & 66.54 & 65.46 & 0.98 & 64.11 & Flexo-shear \\
\hline overlay & SL7SO & 66.36 & 66.85 & 1.01 & 57.84 & Flexo-shear \\
\hline strengthening & SL8SO & 68.26 & 68.04 & 1.00 & 56.47 & Flexo-shear \\
\hline
\end{tabular}

\footnotetext{
${ }^{a}$ Deflection registered at ultimate load in strengthened slabs; ${ }^{b}$ Slab specimen with severe crushing of concrete followed by diagonal shear crack formation; ${ }^{\mathrm{c}}$ Flexo-shear failure mode is considered here, since steel yielding and shear failure was observed after significant deflection.
} 
Table 6. Experimental and Analytical Crack Spacing

\begin{tabular}{|c|c|c|c|c|}
\hline \multirow{2}{*}{ Strengthening } & \multirow{2}{*}{ Slab } & \multicolumn{3}{|c|}{ Average crack spacing, $s_{r m}(\mathrm{~mm})$} \\
\hline & & $\overline{\text { Experimental }^{\mathrm{a}}}$ & & FIB (2001) \\
\hline \multirow{3}{*}{ Reference } & SL1 & 80 & \multirow{3}{*}{$(81)$} & \multirow{3}{*}{93} \\
\hline & & & & \\
\hline & SL2 & 82 & & \\
\hline \multirow[t]{2}{*}{$\overline{\text { CFRP laminate }}$} & SL3S & 45 & \multirow{3}{*}{$(45)$} & \multirow{3}{*}{42} \\
\hline & & & & \\
\hline \multirow[t]{2}{*}{ strengthening } & SL4S & 45 & & \\
\hline & SL5SO & 53 & \multirow{4}{*}{$(52)$} & \multirow{4}{*}{52} \\
\hline CFRP + SFRC overlay & SL6SO & 51 & & \\
\hline \multirow[t]{2}{*}{ strengthening } & SL7SO & 53 & & \\
\hline & SL8SO & 50 & & \\
\hline
\end{tabular}

${ }^{\mathrm{a}}$ Measures taken at the bottom of the slab lateral face (cf. Fig. 10); (value) average value. 
Table 7. Ductility Ratios of the Slab Specimens Tested

\begin{tabular}{|c|c|c|c|c|c|c|c|c|c|}
\hline Strengthening & Slab & $\begin{array}{l}\Delta_{y} \\
(\mathrm{~mm})\end{array}$ & $\begin{array}{l}\Delta_{u}^{\mathrm{a}} \\
(\mathrm{mm})\end{array}$ & $\begin{array}{l}\text { Ductile ratio } \\
\mu_{\Delta}(\mathrm{mm} / \mathrm{mm})\end{array}$ & $\begin{array}{l}\text { Average } \mu \\
(\mathrm{mm} / \mathrm{mm})\end{array}$ & $\begin{array}{l}\chi_{y}^{b} \\
\left(m^{-1}\right)\end{array}$ & $\begin{array}{l}\chi_{u}{ }^{\mathrm{a}} \\
\left(\mathrm{m}^{-1}\right)\end{array}$ & $\begin{array}{l}\text { Ductile ratio } \\
\mu_{\chi}\left(\mathrm{m}^{-1} / \mathrm{m}^{-1}\right)\end{array}$ & $\begin{array}{l}\text { Average } \mu_{\chi} \\
\left(\mathrm{m}^{-1} / \mathrm{m}^{-1}\right)\end{array}$ \\
\hline \multirow[b]{2}{*}{ Reference } & SL1 & 16.76 & 56.59 & 3.38 & \multirow[b]{2}{*}{3.75} & 0.044 & 0.080 & 1.81 & \multirow[b]{2}{*}{2.33} \\
\hline & SL2 & 17.29 & 71.41 & 4.13 & & 0.047 & 0.133 & 2.86 & \\
\hline \multicolumn{2}{|c|}{ CFRP laminate SL3S } & 18.00 & 41.96 & 2.33 & \multirow[b]{2}{*}{2.16} & 0.058 & 0.212 & 3.64 & \multirow[b]{2}{*}{4.00} \\
\hline \multirow[t]{2}{*}{ strengthening } & SL4S & 17.99 & 35.64 & 1.98 & & 0.054 & 0.234 & 4.36 & \\
\hline & SL5SO & 12.20 & 46.93 & 3.85 & & 0.039 & 0.161 & 4.17 & \multirow{4}{*}{3.97} \\
\hline \multirow{3}{*}{$\begin{array}{l}\text { overlay } \\
\text { strengthening }\end{array}$} & SL6SO & 11.65 & 43.95 & 3.77 & \multirow{3}{*}{3.84} & 0.039 & 0.150 & 3.88 & \\
\hline & SL7SO & 12.12 & 47.23 & 3.90 & & 0.040 & 0.152 & 3.81 & \\
\hline & SL8SO & 11.84 & 45.52 & 3.84 & & 0.040 & 0.163 & 4.03 & \\
\hline
\end{tabular}

\footnotetext{
${ }^{\mathrm{a}}$ The ultimate load is taken as the load corresponding to a concrete compressive strain of $0.3 \%$ in the strain gauges on top of slab; ${ }^{\mathrm{b}}$ The curvature values were determined from the data recorded in the measuring devices (SG) situated at the cross-section in the mid span of the slab.
} 


\section{FIGURE CAPTIONS}

Fig. 1. The hybrid strengthening technique for concrete slabs

Fig. 2. Slab strips: (a) test configuration and (b) specimens cross-section dimensions (all dimensions are in $\mathrm{mm}$ )

Fig. 3. Arrangement of displacement transducers and strain gauges: (a) displacement transducers; (b) position of the strain gauges at the CFRP laminate - side view; (c) lay-out of the strain gauges at the steel bars; (d) lay-out of the strain gauges at the CFRP laminate - bottom view; and (e) strain gauges at the concrete slab top surface - top view (all dimensions are in $\mathrm{mm}$ )

Fig 4. Load-deflection behavior at mid-span of all slabs

Fig. 5. Internal strain and stress distribution for the strengthened section under flexure at ultimate stage

Fig. 6. Failure mode: (a) slab strengthened with NSM - slab SL3S; and (b) slab strengthened with NSM and SFRC overlay - slab SL8SO

Fig. 7. Average bond stress $\left(\tau_{b m}^{R L}\right)$ in-between two consecutive strain gauges installed to the CFRP laminate

Fig. 8. Bond stress variation for the slab strips (a) SL4S and (b) SL6SO

Fig. 9. Bottom view of the final crack pattern (a) reference slabs - slab SL1; (b) NSM strengthened slabs - slab SL3S; (c) and (d) NSM and SFRC strengthened slabs - slab SL6SO and slab SL8SO, respectively

Fig. 10. Determination of the average crack spacing $\left(s_{r m}\right)$ in the tested slab strips 


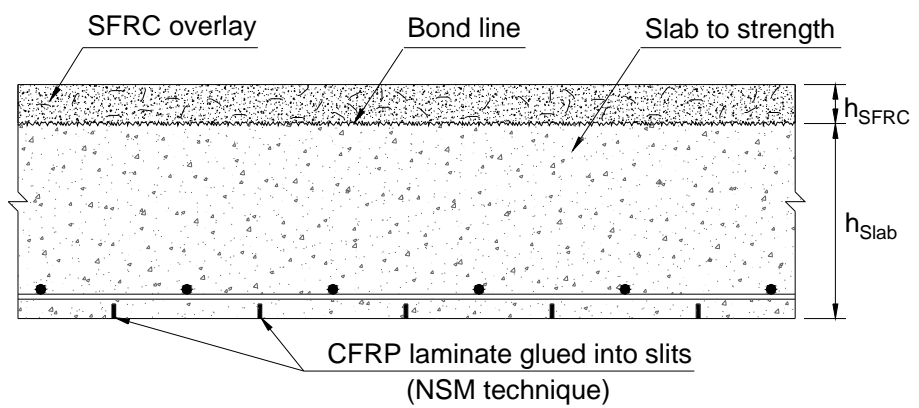

Fig. 1. The hybrid strengthening technique for concrete slabs 


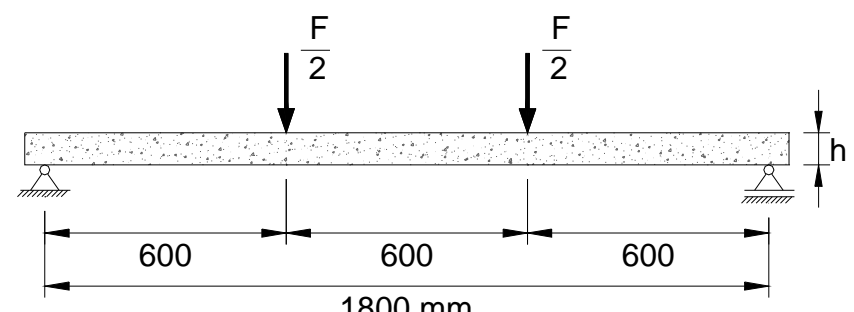

(a)
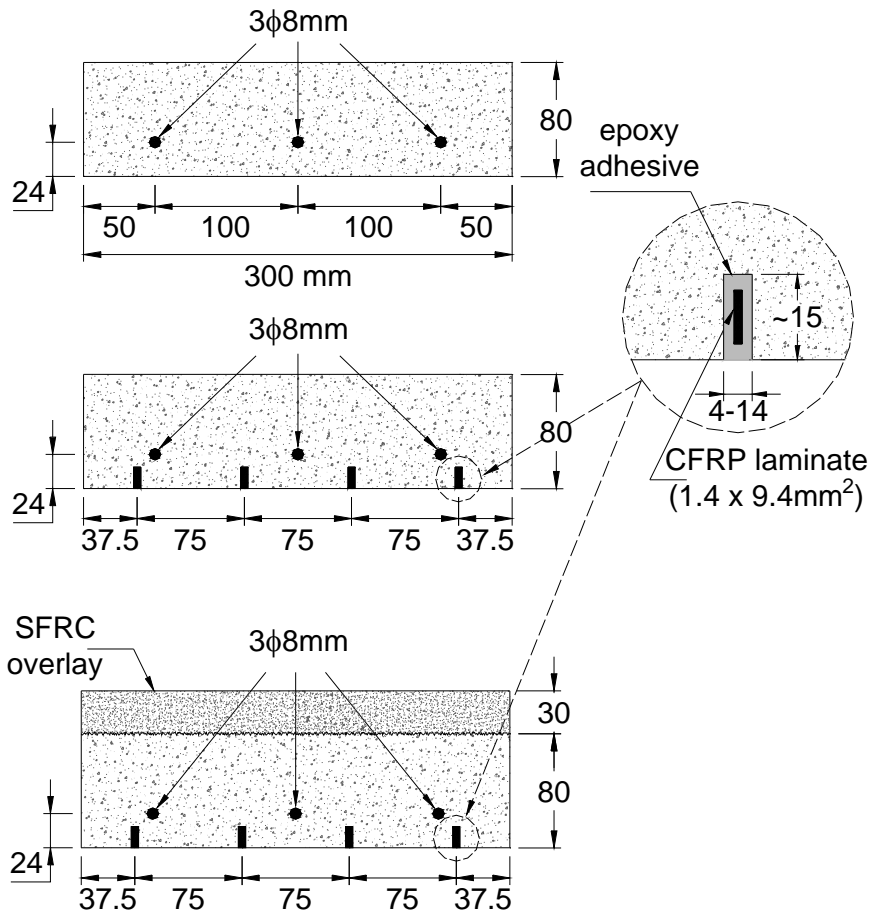

(b)

Fig. 2. Slab strips: (a) test configuration and (b) cross-section dimensions of the specimens (all dimensions are in $\mathrm{mm})$ 
(a)
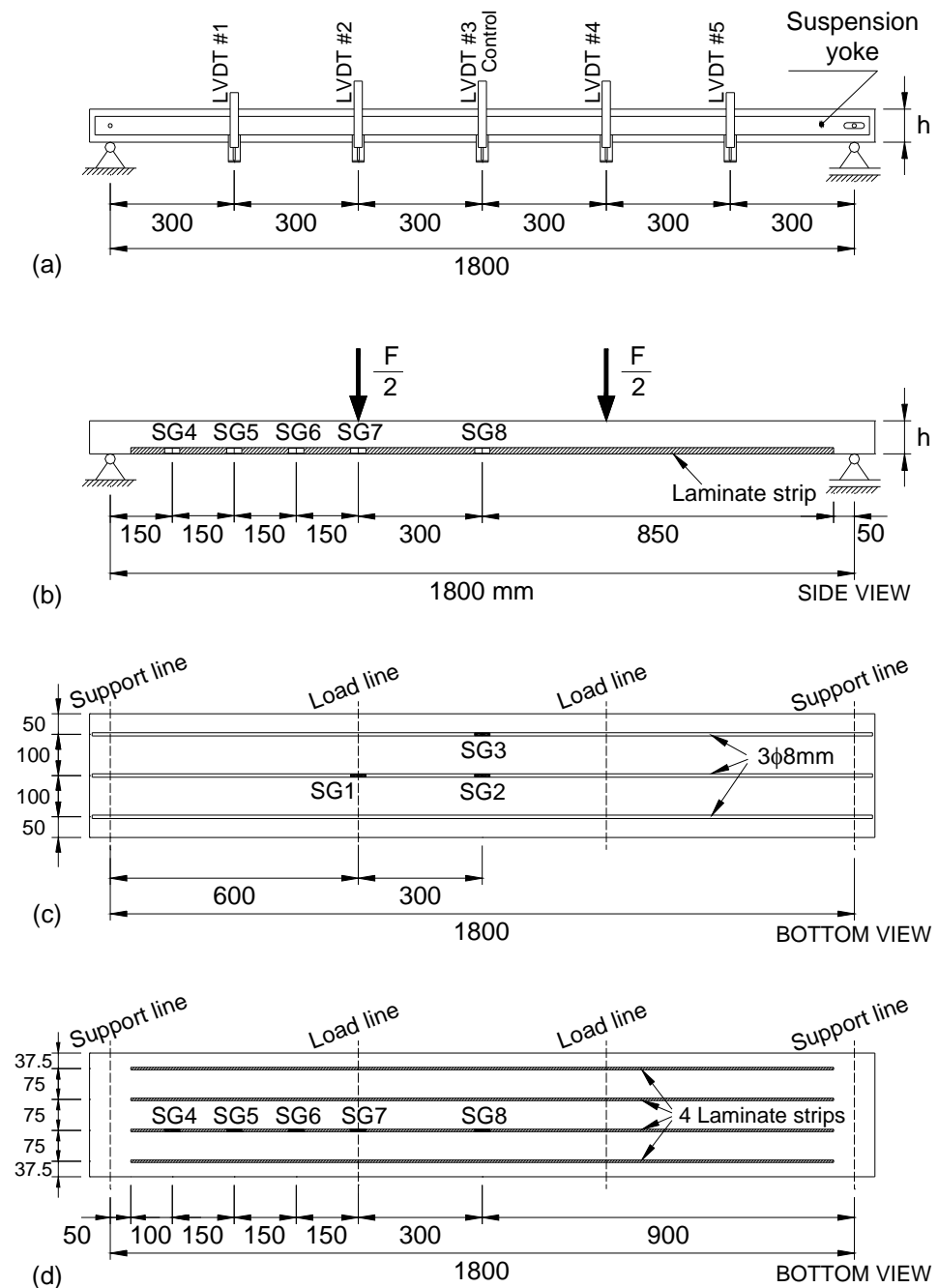

(d)

1800 BOTTOM VIEW

(e)

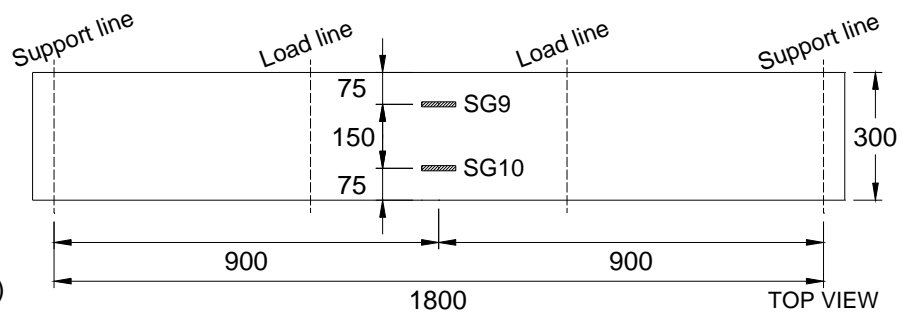

Fig. 3. Arrangement of displacement transducers and strain gauges: (a) displacement transducers; (b) position of the strain gauges at the CFRP laminate - side view; (c) lay-out of the strain gauges at the steel bars; (d) lay-out of the strain gauges at the CFRP laminate - bottom view; and (e) strain gauges at the concrete slab top surface - top view (all dimensions are in $\mathrm{mm}$ ) 


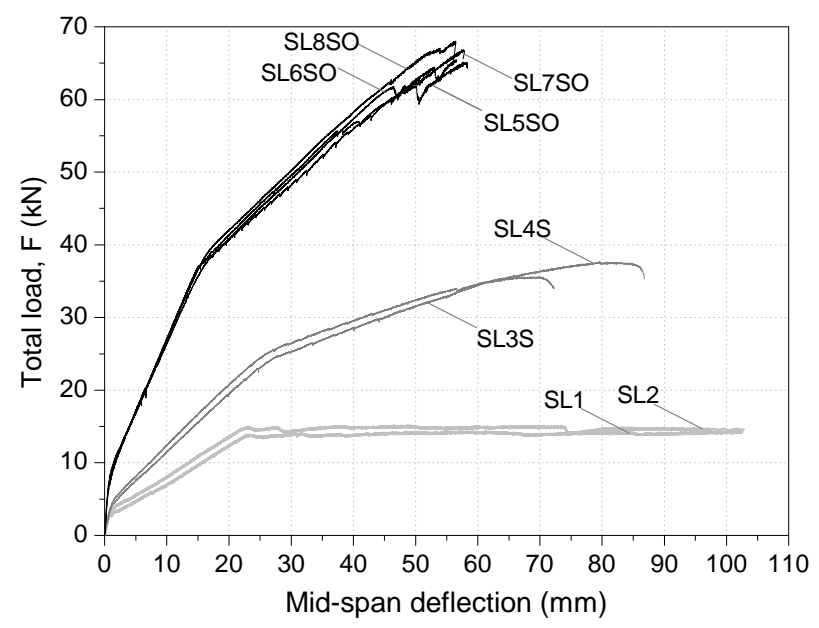

Fig 4. Load-deflection at mid-span of all tested slabs 


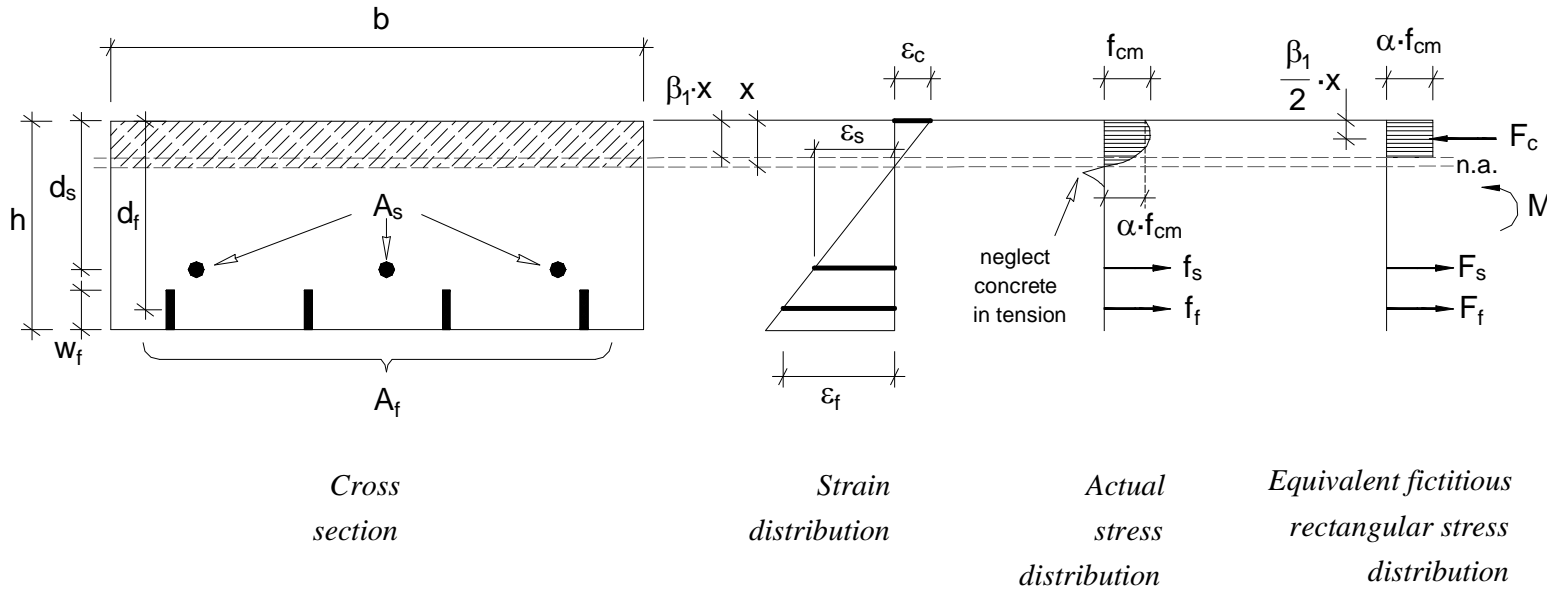

Fig. 5. Internal strain and stress distribution for the strengthened section under flexure at ultimate stage 


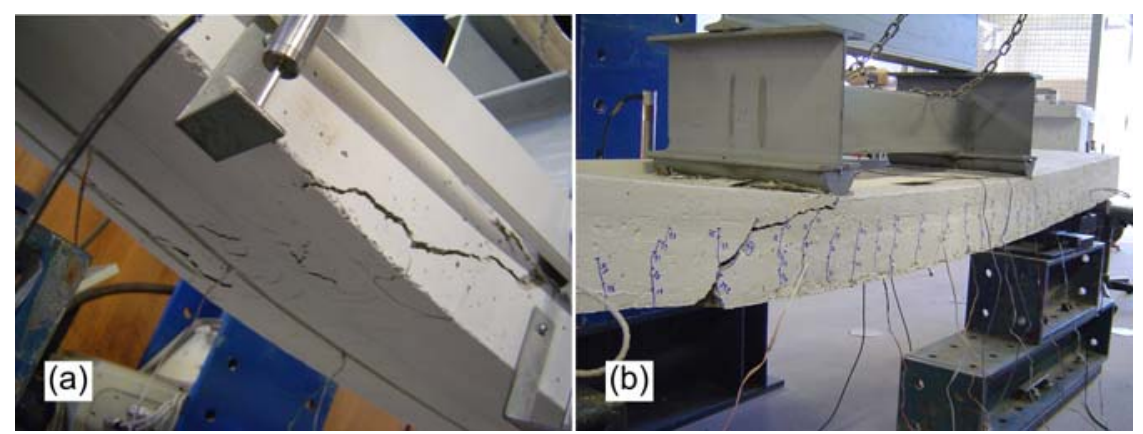

Fig. 6. Failure mode: (a) slab strengthened with laminates - slab SL3S; and (b) slab strengthened with laminates and SFRC overlay - slab SL8SO 


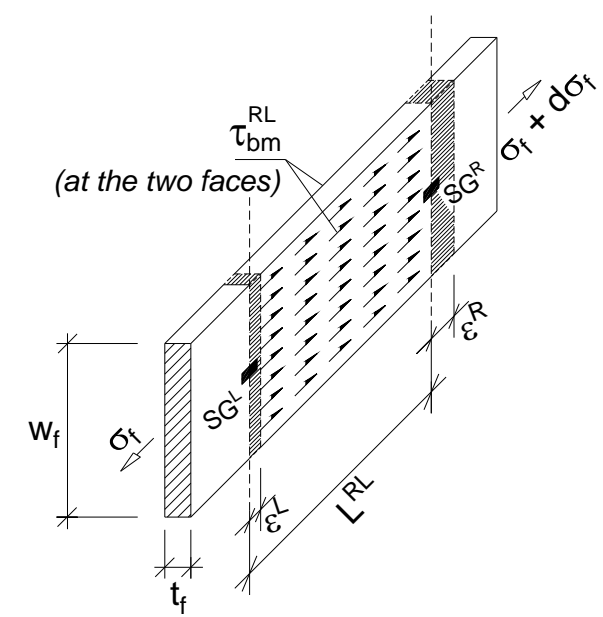

Fig. 7. Average bond stress $\left(\tau_{b m}^{R L}\right)$ in-between two consecutive strain gauges installed to the CFRP laminate 

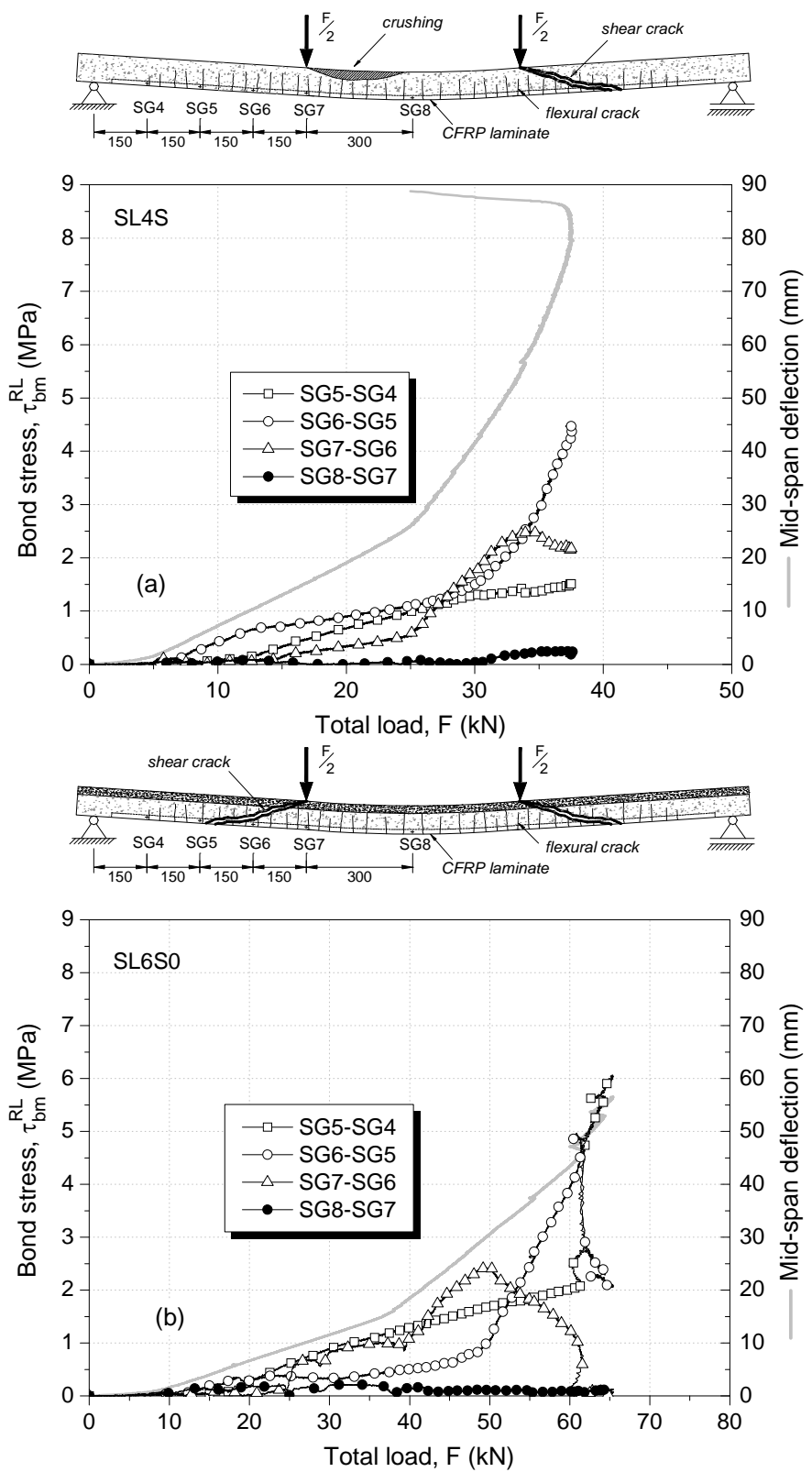

Fig. 8. Bond stress variation for the slab strips (a) SL4S and (b) SL6SO 


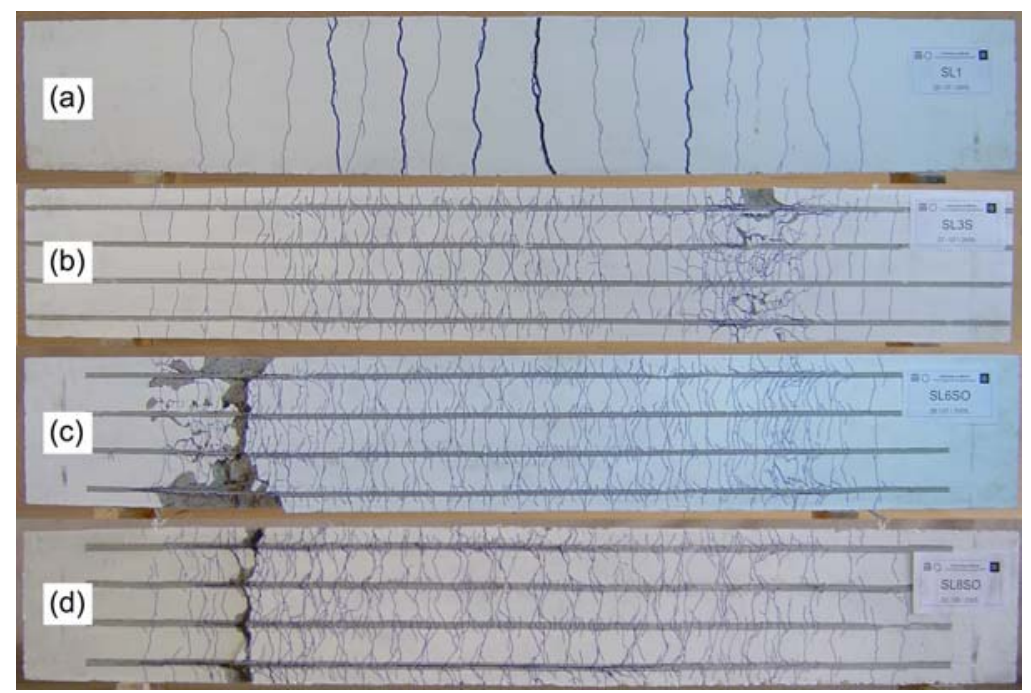

Fig. 9. Bottom view of the typical final crack patterns: (a) reference slabs - slab SL1; (b) NSM strengthened slabs slab SL3S; (c) and (d) NSM and SFRC strengthened slabs - slab SL6SO and slab SL8SO, respectively 


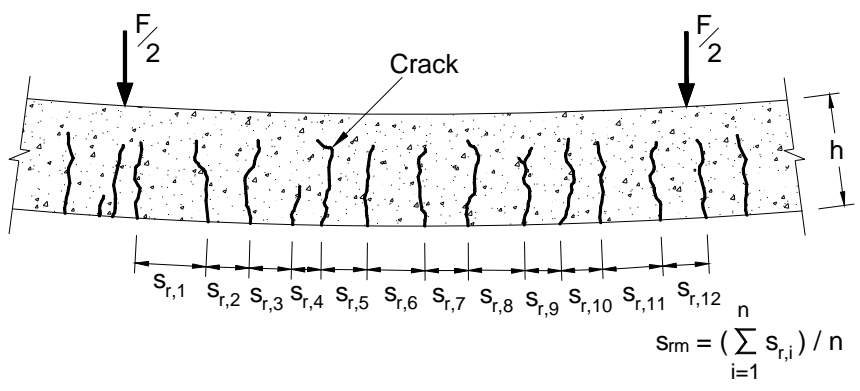

Fig. 10. Determination of the average crack spacing $\left(s_{r m}\right)$ in the tested slab strips 